\title{
Elaboración y resignificación del álbum familiar a través del proyecto de creación en el duelo.
}




\section{DEVELOPMENT AND RESIGNIFICATION OF THE FAMILY ALBUM THROUGH THE ART PROJECT ABOUT GRIEF.}

\section{ABSTRACT}

Domestic photography, with the album as the symbol of the legacy of family memory, has been a reflection of the identity construction and the desire to configure a visual memory in which to project an idealized vision of the family. However, in other periods, images that reflected personal pain, loss or death were accepted as an important part of family memory. Although this field of representation is now becoming visible, especially in the online ground, it is through the art project that many artists talk about grief, disease or death, making these issues visible and normalizing them. In this sense, the object of study here proposed is to analyze two possible approaches in which one documents a new chapter of the family album whereas the second deconstructs and/or resignifies the actual family archive. Along with this proposal various projects by the author are presented in which memory and loss are explored through self-representation and the transformation of the album and the family image, both from theory and artistic practice.

\section{Keywords}

family album; memory; self-representation; grief; death. 


\section{ELABORACIÓN Y RESIGNIFICACIÓN DEL ÁLBUM FAMILIAR A TRAVÉS DEL PROYECTO DE CREACIÓN EN EL DUELO.}

\section{RESUMEN}

La fotografía doméstica, con el álbum como símbolo del legado de la memoria familiar, ha constituido el reflejo de la construcción identitaria y del deseo por configurar una memoria visual en la que proyectar una visión idealizada de la familia. Sin embargo, en otros periodos, las imágenes que reflejaban la muerte, el dolor o la pérdida del entorno fueron aceptadas como parte importante de la memoria familiar. A pesar de que en la actualidad este ámbito de representación se está volviendo a hacer visible, especialmente en el terreno online, es a través del proyecto de creación como numerosos artistas hablan del duelo, la enfermedad o la muerte, visibilizándolos y normalizándolos. En este sentido, el artículo plantea como objeto de estudio dos posibles aproximaciones de este tipo de obras en los que se distingue la documentación de un nuevo episodio de la historia familiar frente a la deconstrucción y/o resignificado del propio archivo familiar. Este examen se complementa con el análisis de diversos proyectos de creación de la autora en los que se explora la memoria y la pérdida a través de la autorrepresentación y la transformación del álbum y la imagen familiar, tanto desde la teoría como en la práctica artística.

\section{Palabras Clave}

álbum familiar; memoria; autorrepresentación; duelo; muerte. 


\section{INTRODUCCIÓN}

Este artículo aborda la fotografía familiar y los procesos de duelo a través del proyecto de creación contemporáneo, analizando el papel fundamental del álbum familiar y la fotografía doméstica en general como reflejo de la memoria visual y de la construcción identitaria del ámbito familiar (Morcate y Pardo, 2016, 2019). A diferencia de la mayoría de archivos domésticos, en los que las imágenes que reflejan el dolor, la muerte y la pérdida del entorno acostumbran a estar eliminadas para no interferir en el relato idealizado para el recuerdo, en los proyectos de creación presentados se ahonda precisamente en este terreno generalmente oculto y denostado con la voluntad de hacerlo visible.

A pesar de la compleja relación que este tipo de imágenes suele tener con el espectador, las fotografías de representación del dolor y la pérdida personal han sido realizadas desde el inicio del medio, oscilando entre la aceptación y el rechazo según la evolución de las diversas actitudes frente a la muerte o la enfermedad y de los valores otorgados a las mismas (Burns 1990; Ruby, 1999; Batchen 2004; Morcate 2013, 2014). En la contemporaneidad, este recelo sigue vigente a pesar de importantes avances en la autorrepresentación y la compartición de imágenes online. Así, la profusión de imágenes cotidianas y a menudo banales, han expandido los límites de aquello que puede considerarse fotografiable y mostrado, ampliando otros aspectos del ámbito privado escondidos durante décadas, vinculándose nuevamente a la expresión del duelo (Walter et al, 2012; Pardo y Morcate 2016; Morcate 2017).

En este estudio, se presentan diversos proyectos de creación que abordan transgresiones y transformaciones del álbum familiar, como parte del contexto en el que este tipo de proyectos son creados por artistas afectados por un proceso de duelo, para confrontarlos con otros realizados por la autora. Estos son fruto de una larga trayectoria de investigación y creación de la representación fotográfica de la muerte y el duelo, en el que se abordan diversos aspectos como la pérdida de la memoria individual y familiar, la enfermedad terminal, la muerte como proceso o el propio proceso de duelo.

En definitiva, el artículo propone elaborar un análisis de este tipo de obras con la finalidad de poner en valor no solo su calidad dentro del ámbito de la creación, sino muy especialmente para exponer su capacidad por normalizar y hacer visible numerosos procesos de duelo. A su vez, estos trabajos pretenden ejemplificar la relevancia e impacto que puede tener la relación del creador de las imágenes con la historia representada. 
2 LA REPRESENTACIÓN DE LA MUERTE Y EL DUELO EN EL ÁMBITO FAMILIAR FRENTE A LA INTERPRETACIÓN DEL ÁLBUM FAMILIAR EN LA MUERTE Y EL DUELO

A pesar de presentarse como un aparente juego de palabras, se pretende aquí establecer ciertas similitudes y diferencias entre numerosas propuestas de creación surgidas de la pérdida en el entorno familiar ${ }^{1}$ en el que todos o algunos de sus miembros son representados por el artista.

La representación explícita del dolor producido por una enfermedad degenerativa y/o terminal, así como del morir y del proceso de duelo ha estado presente en numerosas obras artísticas, fotoperiodísticas y documentales en el medio fotográfico. Sin embargo, conviene distinguir en primera instancia dos posturas diferenciadas que configuran y determinan tanto el contenido como el tratamiento y significado del trabajo: el enfoque distante respecto el enfoque autorreferencial (the Detached versus the Self-referential appoach) (Morcate, 2018). Se entiende el primero como aquel trabajo que aborda alguna de las temáticas expuestas pero que está realizada por un artista o agente externo a la propia historia. Por el contrario, el segundo estaría elaborado por alguien cercano e involucrado directamente en la historia representada, convirtiéndose así en un trabajo autorreferencial y en el que la propia obra se constituye como un proyecto de duelo. El término, acuñado por la autora y analizado en investigaciones precedentes (Morcate, 2014) se define como aquel proyecto de creación motivado y surgido como respuesta a una pérdida.

En este sentido, el artículo se centra específicamente en este segundo grupo de trabajos, por tratarse de proyectos de creación que son motivados por el propio proceso de duelo, en el que su propia concepción y desarrollo son fruto de una reacción frente a la pérdida, a menudo de manera espontánea y no planteada en primera instancia como proyecto de creación. A su vez, estos trabajos desdibujan las líneas habitualmente definidas de la representación del "álbum familiar" o en su sentido más amplio del archivo doméstico, precisamente por cruzar las líneas rojas de aquello que debe ser mostrado, al visibilizar aquellos aspectos familiares que, por contradecir la idea de proyección y representación idealizada de lo doméstico, deben permanecer ocultos y silenciados.

Por otra parte, resulta relevante tener una segunda consideración respecto a la distinción entre este tipo de trabajos, en el que se plantea una clasificación en función de la metodología y ejecución del mismo. De este modo tenemos aquellos proyectos en los que el eje del trabajo radica en documentar y/o crear imágenes específicas que representen una nueva etapa de la vida familiar en la que se presenta la enfermedad, la muerte y/o el duelo, frente a otro tipo de propuestas de creación en las que es precisamente el archivo familiar existente el que se utiliza como materia prima para la elaboración de propuestas de creación que sirvan para expresar el propio dolor así como para cuestionar y replantear el significado cambiante del propio soporte fotográfico. 


\subsection{PROYECTOS QUE ESCRIBEN UN NUEVO CAPÍTULO DEL ÁLBUM FAMILIAR}

Como se apuntaba al inicio del artículo, la fotografía de representación de la muerte, la enfermedad y el duelo han tenido una considerable presencia en el álbum familiar desde su aparición, a pesar de haber llegado a ser denostadas y rechazadas por gran parte del público, especialmente a partir de la segunda mitad del siglo XX. Resulta más que interesante constatar cómo los diversos cambios tecnológicos, como la aparición de la fotografía digital y especialmente del teléfono móvil con cámara, así como la expansión de internet y de sus múltiples espacios (páginas, foros, blogs y numerosas redes sociales) han contribuido a una nueva y mayor aceptación y visibilización de este tipo de imágenes familiares (Pardo y Morcate, 2016). De igual modo se constata una mayor comprensión del propio proceso de duelo, que progresivamente va dejando la exclusividad y encarcelamiento del espacio íntimo y doméstico para volver a convertirse en muchos casos un proceso compartido, vivido en colectividad (Walter, 2015). Dicha experiencia colectiva se experimenta muchas de las veces a través de comunidades virtuales que comparten el mismo tipo de dolor o pérdida. Estos cambios producidos progresivamente con la llegada del nuevo milenio coinciden con una mayor presencia y visibilidad de proyectos de duelo, si bien algunos trabajos pioneros en este ámbito surgen a partir del último tercio de siglo $\mathrm{XX}$, rompiendo muchos esquemas que facilitarían el camino a otros posteriores. Uno de ellos es el proyecto de Dorothea Linch y Eugene Richards Exploding into Life, publicado como libro en 1986, en el que ambos (en un trabajo de escritura e imagen realizado en paralelo), se presenta la historia de Linch quien padece cáncer y explica mediante textos y fragmentos de diario su propia vivencia con la enfermedad. El contenido y tono de sus palabras oscilan entre la aceptación y negación de su proceso, así como también se alterna el tono optimista con otro desconsolado y marcado por el duelo, cuando llega la fase terminal de la enfermedad. Al otro lado de la historia se encuentra su pareja, el legendario fotoperiodista Eugene Richards. Éste retrata su día a día desbordado por su nueva cotidianidad, asaltado por la enfermedad y la pérdida, mediante un enfoque desde lo doméstico, pero manteniendo un tratamiento del proyecto formidables. El fotógrafo consigue aunar la profesionalidad con la sensibilidad de quien es parte protagonista del desmoronamiento de su propia vida personal, pero que al tiempo se sabe testimonio de una historia que merece ser documentada y visibilizada. Un proyecto en el que, al igual que ocurre en trabajos con este mismo enfoque, se compone de imágenes que muestran la historia con gran complejidad, en el que fotografías de gran crudeza muestran los estragos de la medicalización, el dolor y el deterioro físico y psíquico, y se intercalan con otras imágenes más amables en las que los momentos de alegría o de afecto entre los sujetos retratados toman el protagonismo.

De igual modo, otros trabajos como el de Angelo Merendino My wife's fight with breast cancer, iniciado en 2011, sigue la estela de Exploding into Life, desde una perspectiva más contemporánea y global. Aquí, el fotógrafo no sólo retrata el proceso de cáncer de su mujer y su vida en común, sino que además las comparte en internet como una vía para hacer visible la cotidianidad invisible del enfermo y de su cuidador a tiempo casi real, mientras que la protagonista Jennifer, al igual que Dorothea Lynch, plasma sus reflexiones y día a día, pero de una forma pública a través de su blog. Un trabajo, que transita entre el diario (escrito y visual) y el proyecto documental, destacando por su capacidad por conectar con gente anónima que convive con una realidad similar y que reacciona e interacciona con el autor y con otros usuarios, así como contribuye a normalizar la imagen de la enfermedad, de quien la padece y del duelo que la acompaña. 
Entre este tipo de proyectos, también se encuentran, entre otros recientes, el trabajo documental A Life in Death de Nancy Borowich, galardonado entre otros con un World Press Photo en 2016 y posteriormente elaborado como proyecto y libro con el nombre The Family Imprint. La fotógrafa presenta la historia de una pareja Howie y Laurel afectados por el cáncer en el que la narradora no es otra que su hija, quien se enfrenta al deterioro y posterior deceso de sus dos progenitores en un espacio breve de tiempo. El proyecto retrata sin concesiones este capítulo fundamental de la historia familiar, haciéndolo visible más allá del propio entorno doméstico, permitiendo que esta etapa de dolor se inscriba con naturalidad con otras comúnmente fotografiadas y mayormente aceptadas en el archivo familiar. Fuera de este enfoque autorreferencial probablemente, como sucede en muchos otros trabajos, el proyecto se hubiera centrado en retratar la enfermedad misma destacando sus aspectos más visibles, contribuyendo a definir al individuo que la padece (Pardo, 2019).

Como se ha analizado en anteriores investigaciones de la autora (Morcate, 2014, 2018), muchos de estos trabajos no se conciben como un proyecto de creación o fotoperiodístico, sino que nacen como pulsión por plasmar y documentar la cotidianidad como parte de una reacción ante una situación dolorosa y nueva, en la que la cámara sirve como mediadora, como escudo, para hacerla frente. De este modo, Nancy Borowick también apunta:

Photographing my parents' journey started pretty organically. Not knowing how much time we had left together; I knew that I wanted and needed to be with them as often as possible. Photography allowed me a familiar context through which I could better process what was happening while also providing a safety net and distance that shielded me from the actual reality ${ }^{2}$.

Por tanto, y como confirman muchos otros autores es a posteriori cuando esa toma de imágenes se convierte progresivamente en un proyecto, a menudo cuando se ha asimilado la situación o la pérdida.

En este aspecto, este tipo de propuestas tienen un elemento fundamental en común, que no es otro que el desplazamiento de lo íntimo a lo público, dado que su formulación como proyecto de creación, documental o fotoperiodístico tiene como finalidad última el visibilizarse, exponerse y difundirse como obra (Morcate, 2018). Al mismo tiempo, al tratarse de trabajos de creación que abordan lo doméstico desde lo autorreferencial, se erigen como ejemplo de la construcción del propio álbum familiar en el que, por lo general, no se incluyen imágenes de los episodios dolorosos del grupo. Todo ello a pesar de que, en la mayoría de los casos, éstos sean algunos de los capítulos más relevantes de su historia, cambiando no sólo la configuración familiar sino muy especialmente el futuro de sus miembros. De este modo, estos proyectos, consiguen romper algunos esquemas y límites en cuanto a la representación fotográfica del dolor, acercándose a un dolor que puede resultar más común y cercano al espectador, alejándose por tanto de las habituales imágenes de carácter distante y/o violento que suelen inundar los medios de comunicación (Sontag, 2003). Son proyectos fotográficos centrados en retratar un entorno que le resulta cotidiano al fotógrafo y que constituye una visión globalizadora que suele aunar los momentos difíciles y trágicos con otras imágenes en las que se muestran momentos de disfrute

2 "Fotografiar el tránsito de mis padres empezó de una manera bastante orgánica. Sin saber cuánto tiempo les quedaba juntos, sabía que quería y necesitaba estar con ellos lo máximo posible. Fotografiarlos me permitió un contexto familiar a través del cual podía procesar mejor lo que estaba ocurriendo, a la vez que me proporcionaba una red y una distancia que me servía de escudo de la realidad." (Traducción de la autora). Entrevista a la fotógrafa incluida en el dosier de prensa de su página web. http://www.nancyborowick.com/the-family-imprint/the-book/ (última consulta, 21/11/2019) 
o de intimidad que se equilibran en cierta medida con las imágenes que muestran el dolor, el desconsuelo o el morir. Trabajos complejos en los que la diversidad de las imágenes ofrece una visión mucho más cercana y elaborada, con muchos más matices por tratarse de una historia en la que el artista forma parte y se ve afectado por ella.

\subsection{PROYECTOS QUE DECONSTRUYEN Y RESIGNIFICAN EL ÁLBUM FAMILIAR}

Lógicamente conectados con los primeros, pero con una aproximación diferente, los proyectos aquí definidos como "deconstrucciones del álbum familiar" se caracterizan por reelaborar y/o dotar de nuevos significados algunas de las imágenes existentes del archivo doméstico. Por supuesto, en la elaboración de muchas de estas obras se realizarán nuevas imágenes que servirán de contrapunto o ayudarán a la resignificación de las primeras en el duelo y la pérdida. Se trata de proyectos que a menudo surgen del visionado del archivo familiar durante el proceso de duelo, en el que algunas fotografías llegan a conectar de manera especial en la pérdida, produciendo el impredecible punctum (Barthes, 2007), constituyendo así la génesis del trabajo.

Entre los muchos ejemplos, se encuentra el trabajo de Belinda Whiting Sophie's Story (publicado en 2011) en el que después de la muerte de su hija pequeña tras una operación de corazón, la artista reelabora su historia de pérdida. Mediante la narración a modo de cuento para niños y la reutilización de imágenes de archivo de la pequeña, recontextualizadas aquí en el duelo, las imágenes pasan de ser meras fotografías familiares a ser momentos cotidianos de gran valor y perdidos tras la muerte. De este modo, la recopilación de antiguas fotografías familiares de la niña, junto a los textos elaborados tras la pérdida sirven para crear una especie de álbum familiar de duelo que tiene como objetivo hacer visible la pérdida y a su vez rendir homenaje a su hija. Otro enfoque de la reconstrucción de ese archivo familiar lo proporciona Philip Toledano ${ }^{3}$, con el proyecto de duelo When I was six (2015). Este trabajo, narra la pérdida de su hermana cuando era una niña y que surge tras la muerte de sus dos progenitores, a raíz de encontrar en casa de estos unas cajas repletas de objetos pertenecientes a la fallecida. En un intento de recuperar los recuerdos casi olvidados de ese periodo, silenciado y ocultado supuestamente por el bien de la vida familiar, Toledano retoma cada uno de esos objetos y los fotografía otorgándoles un valor de reliquia, en el que un vestido, un dibujo o un mechón de pelo, se mezclan con algunas fotografías familiares apartadas del álbum, algunos escritos de su hermana y nuevas fotografías realizadas por el autor en las que recrea escenas de carácter onírico y espacial que hacen referencia a la forma en la que durante ese tiempo, siendo un niño, él se evadió de la pérdida. Un buen ejemplo de proyecto de creación en el que el propio desarrollo del trabajo sirve para explorar un duelo no concluido pero vital, a la vez que las imágenes cotidianas de su hermana y su familia son remediadas, obteniendo nuevos significados en la pérdida.

Por otra parte, otros proyectos de calado histórico y político reutilizan material de archivo y álbum familiar para trascender la mera historia de dolor personal para erigirse como símbolos de pérdidas colectivas. Un buen ejemplo de ello es el proyecto de Marcelo Brodsky quien en su celebrado Buena Memoria (1997) utiliza fotografías del archivo doméstico para reflexionar sobre el pasado y el duelo, duramente golpeado en su entorno y su propia familia por la dictadura argentina. El proyecto divido en cinco capítulos, toma como uno de los ejes principales una antigua fotografía de grupo de la escuela. En esta imagen escolar, aparentemente banal y coti-

3 Philip Toledano ya consiguió un gran reconocimiento con su trabajo Days with my father (concebido inicialmente en formato blog, pero publicado como libro en 2012), sobre la vida con deterioro cognitivo de su padre y que también constituye un claro proyecto de duelo. 
diana en la que todo espectador puede reflejarse, se hacen visibles mediante marcas y escritos el destino de muchos de ellos. Son sin embargo los rostros tachados los que hacen patente la huella imborrable de la dictadura, designándolos ya no como compañeros de clase sino como desaparecidos. También en este contexto político se produce el proyecto Arqueología de la ausencia (1999-2001) de Lucila Quieto. Un trabajo que surge como una necesidad vital de la artista por obtener una imagen familiar junto a su padre desaparecido (muerto meses antes de que naciera ella, fruto de los asesinatos y las desapariciones forzosas).

Mediante un procedimiento fotográfico extremadamente sencillo a la vez que efectivo, Quieto fotografía en diapositiva la imagen del archivo familiar y la proyecta a gran tamaño, incluyéndose ella misma en el área de luz emitida, consiguiendo la fusión del espacio-tiempo junto a su progenitor. Como comenta la artista, el resultado, "me dio la posibilidad de reparar una situación en imagen, un anhelo que había tenido por muchos años: tener una fotografía con mi viejo" (Niedermaier, 2013, p.75). Esta práctica fotográfica de carácter simbólico se convierte en un ritual de reunión con el difunto, de un modo muy similar al que recurrían algunos dolientes en la segunda mitad de siglo XIX, cuando acudían a un fotógrafo espírito para que consiguieran el supuesto milagro de obtener en una misma placa la imagen del difunto junto al superviviente. Una imagen que supuestamente ofrecería la prueba de una vida después de la muerte y la permanencia de los lazos afectivos entre ambos (Morcate, 2010, 2014).

Más allá de similitudes formales, esta reunión facilitada por la fotografía se extenderá a otros hijos de desaparecidos, transformando ese deseo producido por el duelo individual a un duelo colectivo de gran magnitud, reflejando no sólo historias personales sino su presencia e impacto en la historia.

Por último, ya se ha mencionado como otros trabajos combinan estas dos aproximaciones, en las que por una parte el proceso de duelo genera toda una producción de nuevas imágenes que retratan y documentan nuevas etapas de la historia familiar, mientras que la obra final se desarrolla a posteriori y en la que a menudo se contraponen con documentos de archivo familiar contextualizados con las nuevas imágenes. Mediante este proceso se puede explicar así una historia de un modo más complejo en la que la enfermedad terminal no se convierta ni en la única protagonista ni en el elemento que defina a los retratados. Esto claramente sucede en trabajos célebres como Fotografío para recordar (1991) de Pedro Meyer, en el que además de documentar todo el proceso de cáncer y fallecimiento de sus dos progenitores, el proyecto se presenta con una narración de una selección de imágenes familiares en las que se rinde homenaje a la vida de ambos. De igual modo, también sucede algo similar en el mencionado trabajo de Nancy Borowich quien muestra como trabajo documental las imágenes realizadas por ella durante todo el periplo por la enfermedad y la muerte, pero en la que tanto a raíz de la publicación de su libro The Family Imprint como en su exhibición en diferentes galerías y museos el proyecto se complejiza, incluyendo imágenes del archivo familiar y videos domésticos. Esta ampliación del proyecto tiene la clara finalidad de rendir homenaje a sus seres queridos, ofreciendo una mayor riqueza a la propia historia vital de y entre ambos, en los que la enfermedad y la muerte es un capítulo más del álbum y de una larga vida familiar, a la vez que se presenta como una resistencia a retratarlos como meros enfermos. 


\section{EL TRABAJO DE LA AUTORA COMO ESTUDIO DE CASO}

Se presentan aquí diversos proyectos de creación de la autora por complementar los otros trabajos analizados y por tratarse de obras que deconstruyen y contextualizan el álbum familiar y/o el archivo doméstico, concebidos como proyectos de duelo y elaborados en paralelo como parte de un trabajo de investigación en la creación. Son propuestas que indagan en las posibilidades plásticas y creativas del soporte fotográfico del archivo familiar y que sirven como mediadoras de los procesos de pérdida vividos.

Estos proyectos se han elaborado a lo largo de varios años, en un periodo extenso en el que las vivencias personales y los procesos de duelo derivados de éstas, han propiciado por una parte el desarrollo de estas obras al tiempo que han servido de eje para indagar en la naturaleza de otros proyectos de creación en el duelo elaborado por otros artistas. El trabajo en paralelo de investigación académica y artística ha permitido una mayor profundización de las particularidades, no sólo de cada tipo de pérdida sino también de las estrategias plásticas y visuales utilizadas.

\subsection{F_MIL_ALB_M (ÁLBUM DE FAMILIA)}

En esta primera propuesta, $F_{-}$MIL_ALB_M (álbum de familia) (2017), se aborda la enfermedad de Alzheimer y su duelo a través del archivo familiar de la madre de la artista. Mediante la exploración plástica de las fotografías escogidas, se indaga en los secretos que esconden dichas imágenes y que ya jamás podrán desvelarse porque los conocedores de las historias ya las han olvidado o han muerto. A través de la revisitación de las fotografías escogidas del álbum familiar mediante el tratamiento en el laboratorio, se magnifican los fragmentos perdidos o alterados y los personajes e historias que ya han quedado en el olvido, parecen tomar especial relevancia a causa de la pérdida progresiva de la memoria de su protagonista.

A su vez el trabajo pone en duda la incuestionable capacidad de la fotografía, y especialmente del álbum familiar para preservar el recuerdo y el legado familiar que, sin la protagonista, narradora y albacea de las historias y algunos secretos del mismo, hace que gran parte del contenido relevante de las imágenes se desvanezca sin remedio.

El proceso fotográfico empleado es el fotograma químico en color, trabajado mediante procesos mixtos a partir de las fotografías extraídas del álbum. Como resultado de la manipulación y obtención de los fotogramas se obtienen unas imágenes fragmentadas e intervenidas cargadas de un halo de oscuridad y misterio potenciado por el juego con positivo/negativo de los colores y la pérdida de información y detalle que produce el propio proceso de trabajo (Figuras 1 y 2 ).

Debido a la creación del fotograma químico color, la obtención de la imagen final se realiza en total oscuridad, forzando a buscar el equilibro entre el control y el azar y consiguiendo siempre copias únicas e irrepetibles. La sutileza de cada resultado servirá para mostrar el nivel de nitidez o profundidad que cada interpretación de la fotografía familiar requiere.

F_MIL_ALB_M (álbum de familia) se presenta a su vez como una invitación a cuestionar la fotografía, y especialmente la fotografía familiar, como depositaria inalterable de la memoria, en la que es a menudo la habitual narradora de las imágenes familiares quien consigue dotar 
a cada una de las imágenes del álbum familiar de un contenido que habla más de lo que se oculta detrás de cada escena y que se escapa a la capacidad propia del medio fotográfico para contarnos historias más allá del semblante de los retratados o de la información literal o sugerida que aparece en cada una de las imágenes, a menudo disfrazada u oculta por las convenciones de las propias fotografías en este ámbito.

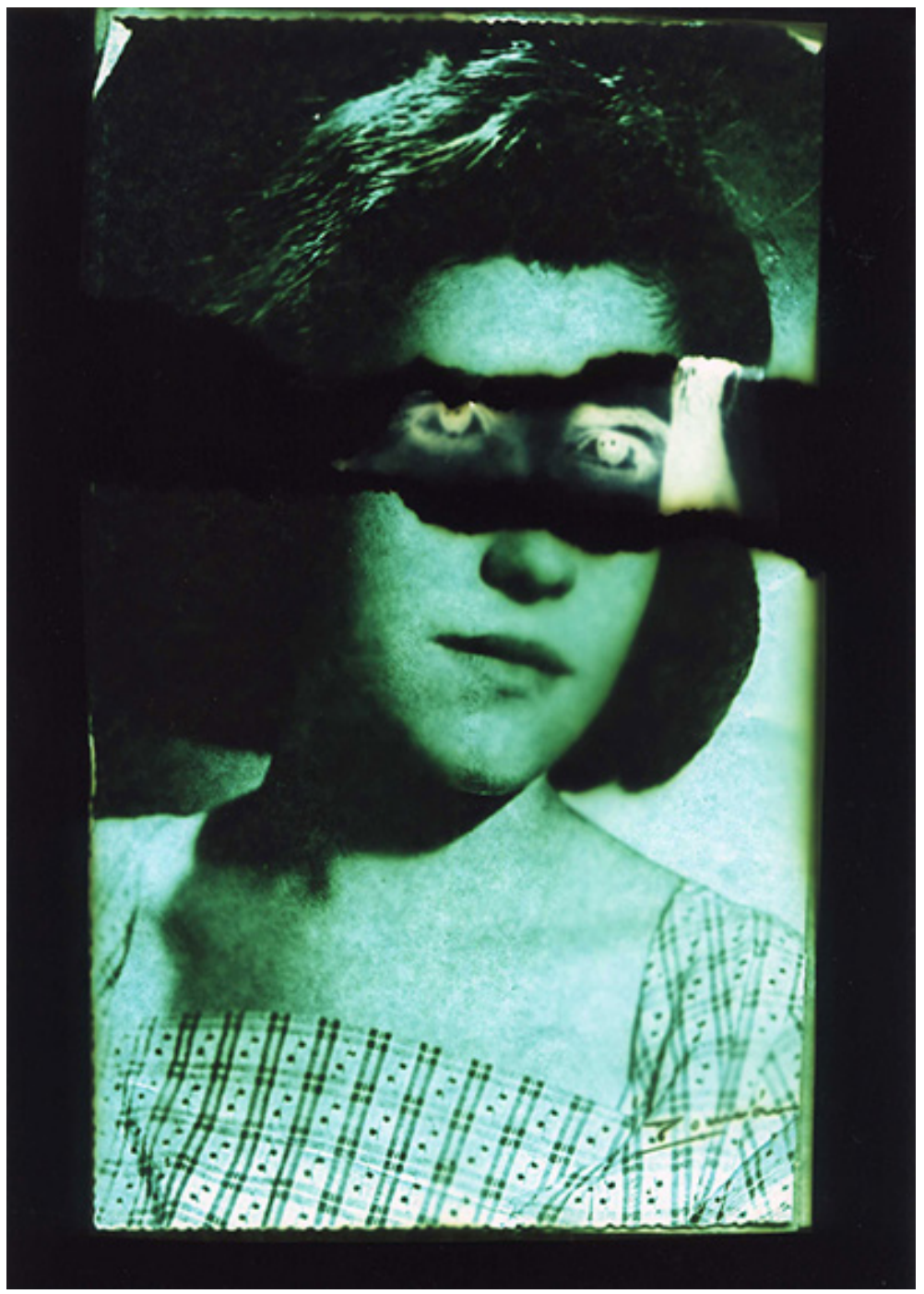

Figura 1. F_MIL_ALB_M (álbum de familia), 2017 de Montse Morcate Fotograma químico color 


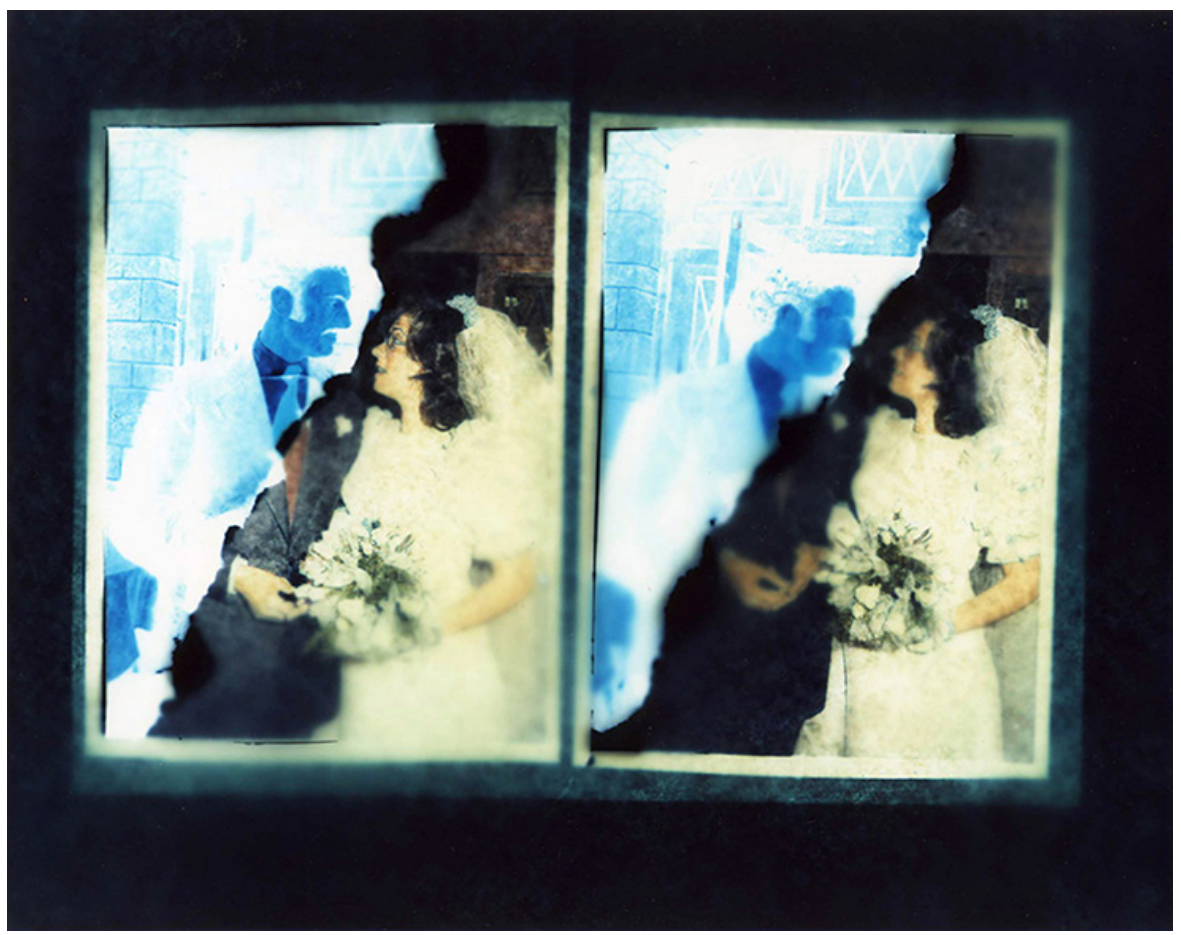

Figura 2. F_MIL_ALB_M (álbum de familia), 2017 de Montse Morcate Fotograma químico color

\section{3} AUTO (RETRATO): APUNTES SOBRE EL ALZHEIMER

El trabajo Auto (retrato): apuntes sobre el Alzheimer (2019), compuesta por dibujos de pequeño formato realizados por la madre de la autora, se centra en el proceso degenerativo del mismo y su duelo a través de su reflejo mediante el proceso creativo. En un estado avanzado de la enfermedad, en la que las obsesiones compulsivas, la drástica reducción de las capacidades cognitivas de memoria y de habla, entre otras, hacen que la relación materno-filial sea compleja, la autora incluye dentro de otras rutinas con su madre la elaboración de un retrato en el que ésta posa para su progenitora. La serie de ilustraciones surge como un proceso comunicativo entre madre e hija, donde la actividad lúdica permite generar una situación divertida y relajada en la que ambas conectan durante unos minutos y en el que la autora a menudo documenta con la cámara esos momentos compartidos.

La idea de proyecto surge después, tras un largo periodo en el que la acumulación de resultados de ilustraciones divertidas y fallidas a su vez (Figura 3), componen un reflejo del proceso de enfermedad y la oscilación drástica en la manera de ver el mundo ( $y$ a su hija) y su modo de representarlo mediante estilos y visiones absolutamente diversas en un lapso breve de tiempo. Gracias al sujeto elegido en las ilustraciones, se muestra también la otra cara de la enfermedad, que no es otra que el cuidador y sus seres queridos, frecuentemente invisibilizados y que deben 
adaptarse a los constantes cambios cognitivos, físicos y emocionales del enfermo, tal y como muestran los dibujos.

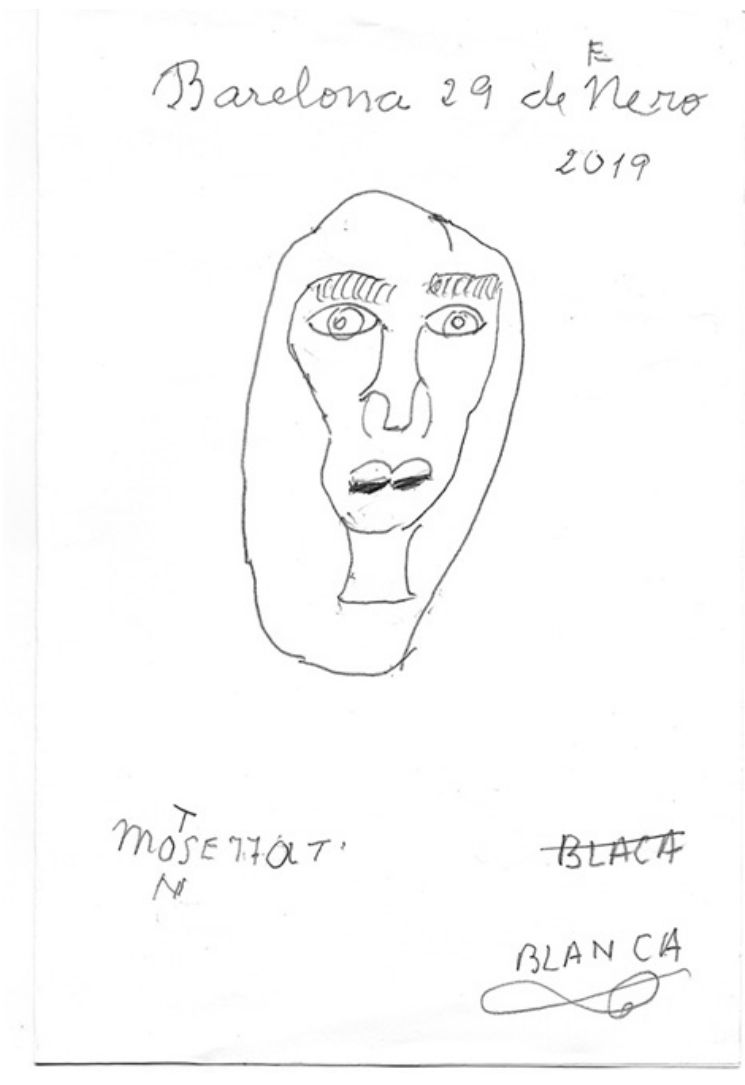

Figura 3. Uno de los dibujos realizados por la madre de la artista. (Auto)retrato: apuntes sobre el Alzheimer, 2019 de Montse Morcate

\subsection{UN ÚlTIMO RETRATO}

Un último retrato, elaborado en diversas fases y finalizado en 2019, es un trabajo que ahonda en el proceso de duelo anticipado (aquel que se inicia antes de la muerte física) y muy especialmente en el intento por construir imágenes que muestren la compleja dualidad de presencia y ausencia del ser querido que se crea en la antesala de la muerte. El proyecto asimismo aborda el concepto de la muerte como un proceso elástico, alejado de la idea de muerte más estereotipada y vista como instante.

El uso del transfer sobre tela a modo de sudario establece un símil conceptual y formal con la Sábana Santa, con la diferencia de que éste es un sudario múltiple que no muestra sólo el rostro final sin vida sino las distintas caras de la muerte (emocional, psicológica y también física) y que 
se reflejan a través de la selección de entre cientos de imágenes realizadas a lo largo de la fase terminal de la enfermedad. Los rostros en las telas aparecen desdibujados como conjuntos de manchas y fragmentos en los que se intuyen no sólo el rostro de la enfermedad y su deterioro sino muy especialmente de la medicalización del proceso de morir y del sufrimiento vinculado al mismo.

Las imágenes desvanecidas de los sudarios son invertidas en una transformación de negativo positivo ofreciendo una aparente mayor visibilidad de la imagen pero que se muestra alterada por el propio proceso creativo en lo que pretende ser una metáfora de la invisibilidad de estos largos procesos del morir tanto para el moribundo como para los seres queridos, así como de las heridas físicas y psicológicas tras numerosos ingresos hospitalarios. Las imágenes translúcidas y oscuras se revelan como pequeñas luces que muestran tímidamente espacios ocultos de dolor en nuestra sociedad contemporánea que relega tanto socialmente como legalmente este tránsito al silencio del hospital.

Para dar visibilidad a estos rostros del sudario se emula el procedimiento que utilizó Secondo Pia en 1898 para descifrar la imagen que escondía la Sábana Santa, fotografiándola y utilizando el negativo como vía para mostrar la imagen positiva. Por tanto, Un último retrato se transforma en una exploración del medio fotográfico y de su capacidad para mostrar lo invisible y ocultar lo visible mediante la dualidad positivo/negativo: fotografía digital (positiva), transferencia mediante grabado sobre tela (negativo) (Figura 4) e imagen negativa a partir del negativo de gran formato (transformada en un positivo) que deja entrever la realidad de la imagen (Figura 5).

El proyecto, por tanto, se convierte en un intento por dar luz a unas imágenes que no quieren ser vistas porque nos hablan de la muerte más silenciada y temida: la muerte no como instante sino como proceso elástico y duradero previo a la muerte final.

El trabajo, complejo en cuanto a su elaboración e investigación con los diversos procesos fotográficos empleando el juego positivo/negativo propone un análisis de la capacidad del medio fotográfico de expresar el duelo mediante sus múltiples variedades creativas. Es, a su vez, un proyecto híbrido también en cuanto a su ejecución, ya que surge de la toma de imágenes durante el proceso de enfermedad terminal del padre de la artista y como parte de una elaboración de un nuevo capítulo de la historia familiar en el que se documenta el día a día afectado por la enfermedad y los ingresos hospitalarios, pero que al mismo tiempo transgrede este tipo de representación de calado más documental para adentrarse en otros terrenos fotográficos y expresivos. 


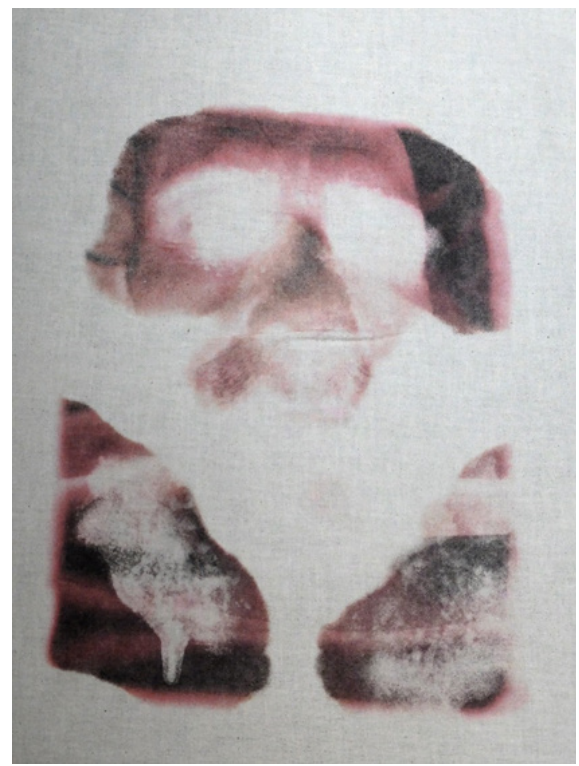

Figura 4. Imagen de una de las telas con la imagen transferida en negativo. Un último retrato, 2019 de Montse Morcate



Figura 5. Placa negativa mostrando la imagen de la tela en positivo. Un último retrato, 2019 de Montse Morcate. 


\section{Conclusiones}

Los proyectos presentados se muestran como un conjunto de respuestas desde la creación que intentan plantear preguntas acerca de la propia naturaleza de la muerte, el dolor, la enfermedad, la pérdida y la memoria familiar y que se enmarcan en los proyectos de duelo. En este sentido, estos trabajos pretenden ofrecer visibilidad y normalizar algunos de los aspectos más complejos y fundamentales que afronta el ser humano en su vida, a pesar de ser generalmente los más ocultos. Son precisamente los trabajos realizados desde un enfoque autorreferencial y muy especialmente mediante la producción de imágenes que documenten procesos degenerativos y la muerte en el entorno familiar, así como el uso de la deconstrucción del álbum familiar y/o la reformulación del archivo doméstico en general, donde se abordan de manera más personal y compleja temas tan sensibles como la pérdida y el duelo. Por este motivo, son precisamente los trabajos realizados desde un enfoque personal, en el que el artista está involucrado y afectado por la historia representada, los que más fácilmente pueden llegar a explorar la complejidad de la misma. Así, estos proyectos suelen alejarse de tratamientos más estereotipados o centrados únicamente en el dolor, hecho más habitual cuando es realizado por un artista no vinculado directamente en la historia. Trabajos que a menudo consiguen reflejar los sentimientos encontrados durante el proceso de dolor y pérdida, mediante imágenes de diversa índole que incluyen los momentos de alegría y desesperación, lo amable y lo abyecto a partes iguales.

De igual modo muchas de estas obras abordan de manera implícita o explícita cuestiones que transcienden su propia historia, como son la fragilidad de la memoria, la memoria individual, colectiva y su vinculación con la historia, así como las limitaciones del medio fotográfico para preservarla, la propia naturaleza del archivo y/o álbum familiar o las estrategias plásticas de creación empleadas para abordar estas complejas cuestiones.

Todos estos trabajos no sólo contribuyen a normalizar la enfermedad, la muerte y el duelo que se produce en el entorno familiar, sino que, a través de sus múltiples expresiones creativas y plásticas, contribuyen a visibilizar la complejidad e infinidad de maneras de afrontar el dolor y la pérdida. Muchos de ellos consiguen así convertirse en referentes visuales para el espectador, permitiendo la identificación con sus propios duelos. Procesos vitales que son absolutamente comunes pero que a su vez son apenas representados y visibilizados. ${ }^{4}$

\footnotetext{
4 Este artículo ha sido elaborado en el marco del proyecto de investigación Cuerpos conectados. Arte y cartografías identitarias en la sociedad transmedia. (Ministerio de Economia y Competitividad. 2018-2020) y la estancia de investigación en el Centre d'Estudis i Documentació del MACBA (2019).
} 


\section{Bibliografía}

Barthes, R. (2007). La càmera lúcida. Mallorca: Lleonard Muntaner Editor.

Batchen, G. (2004). Forget me not: Photography and Remembrance. New York, Amsterdam: Princeton Architectural Press; Van Gogh Museum.

Burns, S. (1990). Sleeping Beauty: Memorial Photography in America. California: Twelvetrees Press, Altadena.

Morcate, M. (2010). La fotografía y el duelo: fotografías de espíritus, post-mortem y otros engaños visuales. En Un art d'espectres: Màgia i esoterisme en el ciema dels primers temps. Girona: Fundació Museu del Cinema- Col·lecció Tomàs Mallol/Ajuntament de Girona.

Morcate, M. (2013). Duelo y fotografía post-mortem: Contradicciones de una práctica vigente en el siglo XXI. En A. Gondra y G. López (Eds.), Imagen y muerte (pp. 25-45). Barcelona: Sans Soleil Ediciones.

Morcate, M. (2014). Duelo, Muerte y Fotografía: Representaciones fotográficas de la muerte y el duelo desde los usos domésticos al proyecto de creación contemporáneo (Tesis doctoral). Facultad de Bellas Artes. Universitat de Barcelona.

Morcate, M. (2017). Tipologías y re-mediación de las imágenes de muerte y duelo compartidas en la memorialización online. Revista M. Estudos sobre a Morte, os Mortos e o Morrer, 2(3), 30-44.

Morcate, M. (2018). Exhibiting Pain, Death and Grief: From the Art Gallery to the Image Shared Online. En E. González-Polledo y J. Tarr (eds.) Painscapes: communicating pain. Londres: Palgrave Macmillan.

Morcate, M. y Pardo. R. (2016). Death, Illness and Grief in Contemporary Photography. En H. Thomas (Ed) Malady and Mortality. Reino Unido: Cambridge Scholars Publishing.

Morcate, M. y Pardo, R. (Eds.) (2019). La imagen desvelada: prácticas Prácticas fotográficas en la enfermedad, la muerte y el duelo. Vitoria- Gasteiz: Sans Soleil Ediciones.

Niedermayer, A. (coord.) (2013). Encuentro de miradas. Fotógrafas argentinas contemporáneas. Buenos Aires: La Azotea Editorial. 
Pardo, R. (2019). Fotografía y enfermedad: iconografías en transformación. En M. Morcate y R. Pardo (Eds.). La imagen desvelada: prácticas Prácticas fotográficas en la enfermedad, la muerte y el duelo. Vitoria- Gasteiz: Sans Soleil Ediciones.

Pardo, R. y Morcate, M. (2016). Illness, death and grief: the daily experience of viewing and sharing digital Images. En Digital Photography and Everyday Life. London, New York: Routledge.

Ruby, J. (1999). Secure the shadow: Death and Photography in America. Cambridge, MA.: The MIT Press.

Sontag, S. (2003). Ante el dolor de los demás. Madrid: Alfaguara.

Walter, T. (2015). New mourners, old mourners: Online memorial culture as a chapter in the history of mourning. Review of Hypermedia \& New Media, 21(1,2).

Walter, T., Hourizi, R., Moncur, W. y Pitsillides, S. (2012). Does the internet change how we die and mourn? Overview and analysis. Omega, 64(4), 275-302. 